\title{
Characteristics of the psychological and pedagogical conditions for the shaping the moral-value field of students
}

\author{
Elena Nikolaevna Smagina* \\ Samara Branch of the State Autonomous Educational Institution of Moscow "Moscow City \\ University”, Stara Zagora Street, 76, Samara, Russia
}

\begin{abstract}
The paper presents a theoretical analysis of approaches to the definition of the concept of "psychological and pedagogical" conditions in educational institutions for shaping the moral-value field of students. The attention of educators and psychologists to the problem of the presence of the necessary conditions conducive to the formation and development of the personality of students has led to the fact that this concept is studied from different points of view, makes it possible to highlight certain characteristics, to get away from the parameters of uncertainty in the scientific and practical aspects. Today, every educational organization is obliged to create conditions conducive to the shaping a personality, spiritual and moral values, socialization of the younger generation. The theoretical analysis of this concept enables to determine and to highlight the most effective conditions in the future, to compare the degree of their effectiveness among the selected ones.
\end{abstract}

\section{Introduction}

The profound changes taking place in the field of education require a comprehensive study. The relevance of this is due to the fact that there are certain losses in the spiritual and moral education of the younger generation, national traditions and devaluation of universal and national values are being lost [1].

The State pays great attention to the solution to these problems. The State policy in the field of education is aimed at updating education on the conceptual foundations of the Strategy for the Development of Education in the Russian Federation until 2025, the Federal State Educational Standard of General Education, and the National Priority Project "Education". One of the mechanisms for the implementation of the State educational policy is the creation of psychological and pedagogical conditions at school, which are necessary for shaping the moral-value field [2].

The analysis of the existing educational activity has shown that for several years in research and pedagogical practice, the question of the need to create psychological and pedagogical conditions for shaping the moral-value field of adolescents has not been

\footnotetext{
${ }^{*}$ Corresponding author: lely57@yandex.ru
} 
sufficiently actualized. Based on this, we consider it necessary to dwell on the theoretical analysis of the categorical apparatus of this concept, highlighting its components and characteristics.

In modern research, the concept of "psychological and pedagogical conditions" is characterized by diversity and uncertainty. In most of the works studied by the author, an attempt to give a definition to the concept is made, but only a list of conditions, the effectiveness of which is proved within the framework of the conducted formative experiment, is offered.

N.G. Bazhenova and I.V. Khludeeva consider pedagogical conditions as "phenomena necessary for the onset of a given event, but not causing it by themselves" [3].

A more specific definition in the aspect of the problem under consideration is found in the pedagogical dictionary. Here, conditions are understood as "a set of variables of natural, social, external, and internal influences that effect the physical, mental, moral development of a person, his/her behavior, education, and training, personality formation" [4].

In psychology, the conditions of activity are classified into external and internal. The external ones include: motivational, personnel, material and technical, scientific and methodological, financial, organizational, regulatory, and informational conditions. Internal ones include the characteristics of the subject of activity, without which the performance of the activity is impossible (for example, professionally important qualities, personal characteristics, abilities, skills, experience, readiness for activity, etc.).

In pedagogy, social and natural conditions, objective and subjective, general and specific are distinguished. Psychological and pedagogical conditions are defined as a kind of pedagogical conditions.

In this paper, the author proposes to consider the theoretical analysis of the concept of "psychological and pedagogical conditions" in the scientific literature.

\section{Literature review}

Analysis of the scientific literature, theses has shown that the psychological and pedagogical conditions for the formation and development of a student's personality can be classified on different grounds.

1. E.P. Loskova [5] and A.V. Lysenko [6] highlight the methodology of education: conceptual foundations, scientific theories and approaches that underlie the educational process being implemented.

2. According to V.V. Nikolina [5], psychological and pedagogical conditions include the main legislative acts and initiatives for the formation of a regulatory framework for the processes of teaching and parenting.

3. A.A. Egizaryants [7], K.G. Kuznetsov [8] substantiate the presence of components of the content of education: basic educational programs of schools, work programs of subjects and academic disciplines, didactic tools, control and evaluation tools, substantive aspects of education quality control processes; planned educational results of students.

4. The technological component of the educational process: forms, methods, technologies, techniques of teaching and parenting [9].

5. Implementation of the principles of the educational process individualization as a mandatory consideration of individual psychological qualities in the educational activities of students (A.S. Berberyan [10]).

6. Favorable socio-psychological climate in the child-adult team and in the educational institution as a whole (E.V. Ignatovich [11]).

7. Openness of educational activities: ensuring access to the necessary information for all subjects of educational relations (S.V. Shestopalov [12]). 
8. Necessary and sufficient professional competencies of the teaching staff, personal characteristics of educators (P.T. Dolgov [13], A.V. Lysenko [6]).

9. Creation of educational and developmental environment of the institution (I.A. Zimnyaya [14], A.K. Vishnyakova [15]).

10. Family and school collaboration (T.N. Pozdnyakova [16]).

11. Social partnership, network interaction of educational organizations (general and supplementary education), cultural and public organizations, various social institutions on training and education (A.P. Sukhonosov [17]).

13. The moral potential of the social macro- and microenvironment [18].

\section{Materials and methods}

The theoretical substantiation of the problem stated in the subject of the paper is based on the principles of scientific character, consistency, comparative analysis of research approaches to the definition of a concept, highlighting its characteristics, and synthesis of various scientific concepts.

The works of domestic and foreign researches in the fields of scientific knowledge, such as philosophy, axiology, pedagogy (parenting theory), and personality psychology have formed the basis for determining the components of the moral-value field of students. The study of the relevant scientific-methodological and reference literature (in particular, on the study of the experience of creating psychological and pedagogical conditions at school) made it possible to single out the set of psychological and pedagogical conditions necessary for its formation.

\section{Research results}

The results of the theoretical study allowed us to consider the selected conditions in the aspect of shaping the moral-value field of students in schools.

\section{Methodological Basis of Education.}

FSES of general education as a methodological basis highlights the need for the implementation of personality-oriented, system-activity, and competent approaches [19]. A certain character of novelty in the organization of educational activity is introduced by the system-activity approach. Its implementation is as follows:

1) training and education is aimed at a certain result;

2 ) in the course of training, systemic knowledge of the world occurs (the objects of knowledge themselves act as systems). This determines the introduction of meta-subject content in education;

3) cognition of the world occurs in one's own activity, which ensures a practice-oriented nature of training. When designing and implementing the educational process, the components of the psychological structure of students' activities should be taken into account: motive, goal, method of action, result;

4) a student is a subject of the activity and, therefore, is in an active position towards the World, the Other, himself/herself. In this case, activity is understood as the interaction of a person and the world, during which a person consciously and purposefully changes the world and himself/herself;

5) the content of training and education should take into account the individual and psychological-age characteristics of students, their leading activities;

6) availability of feedback mechanisms. The content of the training is constantly being supplemented and changed based on the availability of objective conditions for the implementation of educational activities. Feedback (in the form of various assessment and 
control measures) allows drawing conclusions about how the content of education should be changed in order to make it more effective for shaping the moral-value field of students.

Thus, on the basis of the system-activity approach, shaping the moral-value field presupposes a conscious acceptance of moral values by students; it is carried out in their own activities, through actions, deeds corresponding to universal human values; it is implemented in the course of communication as a leading activity for adolescence; it is carried out systematically, throughout the entire period of study, with the involvement of classmates, educators, families, as well as educational, cultural, and public organizations in this process.

\section{Regulatory Framework for Education.}

Legislative acts: the Federal Law On Education in the Russian Federation, the Federal State Educational Standard of General Education, the Strategy for the Parenting Development in the Russian Federation for the Period up to 2025, the National Project "Education" (2019-2024) regulate the process of parenting the younger generation for the present stage.

In Article 2 of the Federal Law On Education in the Russian Federation to be specified: "Education is an activity aimed at personal development, creating conditions for selfdetermination and socialization of students on the basis of sociocultural, spiritual and moral values, as well as rules and norms of behavior adopted in Russian society in the interests of a person, family, society, and the State, the formation in students of a sense of patriotism, citizenship, respect for the memory of the defenders of the Fatherland, and the exploits of the Heroes of the Fatherland, law and law enforcement, a man of labor and the older generation, mutual respect, respect for the cultural heritage and traditions of the multinational people of the Russian Federation, nature and the environment".

The main provisions of the Federal State Educational Standard of General Education aim pedagogical collectives to create conditions that are aimed "at ensuring the mastery of the spiritual values and culture of the peoples of Russia. "The conditions for the implementation of the basic educational program of basic general education should provide $\langle\ldots\rangle$ the opportunity $\langle\ldots\rangle$ to shape sociocultural and spiritual and moral values of students" [19].

The Strategy for the Parenting Development in the Russian Federation for the Period up to 2025 sets the value guidelines for the parenting process, which should be reflected in the format of educational results of students in the form of personal characteristics and psychological qualities: patriotism, conscience, duty, kindness, mercy, etc.

The National Project "Education" (2019-2024) defines a strategic goal-the upbringing of a harmoniously developed and socially responsible individual based on the spiritual and moral values of the peoples of the Russian Federation.

Normative documents confirm the priority of the value-based approach in parenting. Proceeding from this, a certain organization of the educational process based on the strategic provisions of legislative and regulatory documents becomes a mechanism of shaping the moral-value field of students.

3. Learning Content.

Analysis of scientific works on the problem of shaping the moral field and values of students (L.M. Abolin, I.V. Vinogradova, V.A. Golovanov, T.U. Gochiyaeva, T.P. Krasnova, I.V. Moskalenko, L.V. Moshkina, I.M. Remorenko, M.Yu. Statsevich, A.A. Sharonov, and others) has shown that the content of educational programs shaping the values in students implemented by educators of educational organizations includes the following components:

1) cognitive (an educator transfers to students knowledge about values, personalities, historical events, cultural traditions, and other information that allows students to shape a holistic view of the content of a particular value); 
2) emotional (an educator gives students a sample of a certain evaluative attitude to value and to the forms of its manifestation; he/she shapes an emotional attitude to value);

3) activity-based (an educator involves students in activities in which the studied values are maximally represented, forms the ability to determine value in a particular situation, to assess people's behavior from the standpoint of values);

4) reflexive (an educator engages students in critical comprehension of values, puts them in a situation where they should make a moral choice, evaluate their behavior in terms of conformity to values) [20].

Also, some researchers highlight an additional motivational component (determination by students together with an educator of goals in life, which are based on values).

Thus, the content of the educational process, programs for shaping the value sphere of adolescents (these may include basic educational programs, work programs in subjects, programs of extracurricular activities, supplementary general education programs, educational programs, etc.) most often determines the idea of value as an attitude of the personality [21]. Accordingly, the psychological structure of the attitude determines the direction and content of the teacher's work on shaping moral values in students.

\section{Forms, Methods, Technologies, Techniques of Teaching and Parenting.}

Shaping the moral-value field of students requires educators to use both generally accepted pedagogical methods and technologies, as well as various types and forms of classes (disputes, discussions, non-traditional lessons), the organization of project activities (collective, group, individual). In the format of educational activities implemented in traditional pedagogical practice, meetings with interesting people, educational excursions, thematic competitions, cultural and leisure activities, public open lectures with further discussion are considered effective [21].

As a special method, means, technology, domestic educators and psychologists single out dialogue as a tool of shaping the moral-value field of adolescents. At the same time, a distinction is made between external (between interlocutors) and internal dialogue.

The internal dialogue, which unfolds in the inner space of the personality, is of particular importance for the development of the personality's consciousness, its spiritual and moral values, is considered to be as a mechanism for the interaction of the semantic positions of consciousness and it is realized as a mental dialogue with a significant other(s).

The forms, methods, technologies, techniques of teaching and parenting of the moralvalue field of adolescents should be selected in such a way that they stimulate the internal dialogue of students.

\section{Individualization of the Educational Process.}

The teacher's work on shaping the moral-value field of the student's personality is aimed at taking into account the individual psychological qualities of students, the level of their moral development.

Traditionally, educators and psychologists (S.P. Akutina, N.V. Batakova, Kh.Kh. Valiakhmetov, N.Kh. Gilmutdinova, E.M. Molchan, R.V. Ovcharova, N.P. Ochirova, E.V. Statkevich, L.S. Stepanova, T.M. Churenkov, and others) distinguish three levels of development of the moral field, spiritual and moral values: high, medium, and low ones. The basis for assigning a student to one level or another is based on the following criteria: passivity - activity; independence - dependence of judgments; level of self-awareness; the level of development of the cognitive, emotional, and activity components of the moral field, the ratio of the level of development of these components (the nature of moral judgments; knowledge of the content of values, cultural norms; attitude towards other people, the ability to evaluate their own and other people's actions; the level of development of empathy, emotional intelligence; volitional regulation of behavior; motivation for self-development and moral behavior; moral actions; compliance with the rules of conduct); individual hierarchy of value orientations [22]. 
For our study, adolescence, the age of the formation of individual values, is of the greatest interest. In adolescence, the moral-value field is intensively developing due to the development of thinking, consciousness, reflection, self-awareness.

It is obvious that the teaching and educational process should be built taking into account the characteristics and new formations of age.

6. Favorable Socio-Psychological Climate in Children and Adults and in the Educational Institution as a Whole.

The creation and maintenance of a favorable socio-psychological climate in an educational institution is one of the tasks in the activities of the administration, pedagogical, children's, and parental teams.

The climate is:

- a set of characteristics that describe the situation in the school (in the classroom) (for example, the degree of independence of students' actions, the amount of control over the involvement of students in activities, etc.);

- features of interaction in the "teacher-student" system (internal regulations and a system of requirements, a system of rewards and punishments; the level of mutual support, mutual assistance, emotional affection in relationships, the attention of team members to each other; respect, goodwill in relationships, politeness; style of pedagogical leadership, style of teaching; opportunities for creativity; "group morality", value attitudes of members of the school team [11]).

For shaping the moral-value field, these characteristics should meet the requirements of the humanistic paradigm of education, a personality-oriented approach in education, and developmental learning, since the socio-psychological climate of the educational organization significantly effects the academic achievements of students, on motivation, on the formation of the personality of schoolchildren.

7. Openness and Publicity of Educational Activities.

This condition implies providing access to information for all subjects participating in educational relations. Publicity ensures the state-public nature of relations and the possibility of the influence of all interested partners on the quality of the created and implemented psychological and pedagogical conditions at school [22].

8. Professional Competencies of the Teaching Staff of the Educational Organization.

Today, professional training (knowledge, skills, and competencies) and personal characteristics of the teacher make up the system of requirements of the Occupational Standard of pedagogical activity.

According to a number of researches (A.V. Gushchina, E.F. Zeer, V.A. Krutetsky, A.K. Markova, I.A. Zimnyaya, E.I. Rogov, L.M. Mitina, and others), a teacher should have professionally significant qualities, which include:

- pedagogical abilities (managerial, academic, methodological, social, analytical, design, predictive);

- pedagogical orientation of the personality; pedagogical tact; pedagogical goalsetting, thinking, and reflection;

- a set of certain psychological qualities: sociability, responsibility, dedication, creative thinking, team building, striving for self-improvement, empathy, etc.;

- awareness of the model of their profession, professional self-assessment; personal readiness for pedagogical activity;

- moral foundations of professional activity: ethical knowledge, moral qualities (conscientiousness, decency, duty, mercy, kindness, love, etc.) [23].

9. Educational and Developmental School Environment.

A special role for the formation of a student's personality, according to V.A. Yasvin, belongs to the educational environment. 
For a schoolchild, the environment is not only the subject-material environment, but to a greater extent the so-called social environment. In the logic of student-centered learning, the organization of the educational process, which is based on the relationship developing between the teacher and the student, and cooperation between them, will play a special role in shaping the moral-value field.

According to V.A. Yasvin, the educational environment of the school is modeled, in accordance with the generally accepted vector model, which is represented by a rectangular coordinate system, where the $x$ coordinate is "freedom - dependence" and the $y$ coordinate is "passivity - activity". "Activity" is assessed by the initiative of the subjects of the educational process, their persistence in achieving goals, defending their interests. "Freedom" is manifested in the independence of assessments and judgments of participants in educational relations from external influence, self-dependence, and independence of choice [24].

Depending on the position of the educational environment in this coordinate system, various types of educational environments are distinguished.

Shaping the moral-value field of the adolescent is facilitated by educational environments located in the quadrant [freedom; activity], that is, an environment that allows the student to freely and actively develop.

10. Organization of Interaction between Family and Educational Institution.

Many educators consider the interaction of a teacher and parents as a necessary condition for the spiritual and moral education of schoolchildren (V.N. Vershinin, A.Ya. Danilyuk, N.E. Prodiblokh, A.M. Rusetska, and others).

The main tools for the development of the moral-value field of students are recognized as social partnership between the school and parents' associations, as well as the dialogue between the homeform teacher and the parent.

11. Social Partnership, Network Interaction of Educational Organizations (General and Supplementary Education), Cultural and Public Organizations, Various Social Institutions on Training and Education.

For shaping the moral-value field of students' personality, educational organizations build network interaction and cooperation with various organizations, unions, public associations, industrial enterprises, etc. This allows the use of additional resources (personnel, information, methodological, didactic), material and technical base of network participants, presents other opportunities for synergy in the educational process [25].

\section{The Moral Potential of the Social Macro- and Microenvironment.}

The social microenvironment (school collective, family, friends, peers, a student's social circle) and the macroenvironment (the country's economy and politics, social institutions, mentality, culture) have both invariant and variable characteristics that can contribute or hinder shaping the moral-value field student.

Family and family education is an important factor in the microenvironment. Research shows that children learn from their parents their values and behaviors. Defects in family education distort the moral-value field of the child [26].

An equally important factor is the psychological qualities of a teacher. Teachers with conscious life-meaning orientations use the mechanisms of psychological influence on students - persuasion, infection, and imitation; in a conflict situation, they use strategies"taking responsibility", "self-control", "problem solving”. Teachers with poorly perceived life-meaning orientations use suggestion and coercion to influence schoolchildren, and in a conflict situation, they use the strategies of "avoidance", "distancing", "rivalry" [27].

Thus, teachers and parents who demonstrate in communication with a child a focus on finding and realizing the meaning of life, aimed at appropriating spiritual values, create more favorable conditions for the parenting and development of the moral-value field of a student. 
The third significant factor of the microenvironment that effects the assignment of moral values to students is the peer group with which they identify themselves. Shaping the moral-value field of the student will depend on the orientation of this group (socially positive or socially negative) [28].

The most significant for the moral development of adolescents, according to R.V. Ovcharova and E.R. Gizatullina, are the characteristics of the microenvironment:

- the culture of educators and parents, the representation in their behavior of models of moral behavior and moral relations;

- accessible explanation to students of the essence of moral norms.

Macroenvironmental factors create opportunities for shaping the moral-value field of adolescents, primarily through the values presented in the culture of the people [22].

The theoretical analysis has shown that for shaping the moral-value field of students in educational organizations, it is necessary to create a complex of psychological and pedagogical conditions. It is obvious that the psychological and pedagogical conditions in various educational institutions are not completely the same; they contain both similar (specified by regulatory documents, Russian pedagogical tradition) and different (determined by the internal characteristics of the subjects of educational relations) conditions. We have failed to find an evidence base on which psychological and pedagogical conditions of shaping the moral-value field of schoolchildren can be classified as effective.

Hence, based on the conducted theoretical analysis, a research question arises: which of the psychological and pedagogical conditions existing in the modern basic school most effectively form and develop the moral-value field of today's adolescents? The search for an answer to this question has identified the problem of empirical research - the definition of effective psychological and pedagogical conditions of shaping the moral-value field of an adolescent.

\section{Conclusions}

The theoretical analysis of the problem of the presence of the conceptual apparatus of psychological and pedagogical conditions for shaping the moral-value field of adolescents has shown the existence of various approaches to the definition, the multiplicity of characteristics of these conditions. In educational institutions, a complex of psychological and pedagogical conditions is being created, as evidenced by a large bank of thesis works. The current state of development of the education system in the Russian Federation sets a system of certain requirements for psychological and pedagogical conditions through the implementation of the State educational policy. This, undoubtedly, requires a detailed theoretical analysis based on existing scientific theories, concepts, approaches, and pedagogical practice. This paper attempts to present the work done in this area. In our opinion, a feature of this stage of work was the identification of the characteristics of conditions that are most significant for modern education. In the future, under the empirical study, it is planned to substantiate the presence of certain conditions in educational institutions of Samara Region, to conduct a comparative analysis for specific schools, to identify deficient conditions, and to determine effective ones as a systemic mechanism of shaping the moral-value field of adolescents.

\section{References}

1. N.D. Nikandrov, Russia: Socialization and Education at the Turn of the, 304 (Pedagogical Society of Russia, 2000) 
2. A.G. Asmolov, Bulletin of Education, 1, 65 (2008)

3. N.G. Bazhenova, I.V. Khludeeva, Izvestiya of Herzen University, 151, 217 (2012)

4. V.M. Polonsky, Dictionary of Education and Pedagogy, 512 (2004)

5. V.V. Nikolina, E.P. Loskova, Spiritual and Moral Education of a Person: Traditions and Modernity. Materials of the International Scientific and Practical Conference, 450 (2018)

6. A.V. Lysenko, Psychological and Pedagogical Conditions for Shaping the Professional and Value Orientations of Future Music Teachers, 13.00.08., 25 (2005)

7. A.A. Egizaryants, Psychological and Pedagogical Conditions for the Formation of Ethno-National Tolerance in Adolescents, 19.00.07., 24 (2005)

8. K.G. Kuznetsov, Psychological and Pedagogical Conditions for the Development of High School Students' Independence in Planning Personal Professional Prospects, 19.00.07., 26 (2012)

9. L.S. Stepanova, Education of Moral Personal Qualities in Students in the School Educational Process, 13.00.01., 18 (2009)

10. A.S. Berberyan, Psychological Problems: Characteristics, Principles of Classification and Diagnosis (2019)

11. E.V. Ignatovich, Pedagogical Conditions for the Formation of a Moral and Psychological Climate in an Educational Institution, 13.00.01., 24 (2005)

12. S.V. Shestopalov, Shaping the Moral Values of High School Students in the New Information Space, 13.00.01., 22 (2008)

13. P.T. Dolgov, Psychological and Pedagogical Conditions for the Formation and Development of Motivation for the Professional Growth of a Leader (on the Example of Educational Institutions), 19.00.07., 19 (1999)

14. I.A. Zimnyaya, Problems of the Quality of Education, Its Rationing and Management, Collection of Scientific Papers, 83 (1999)

15. A.K. Vishnyakova-Vishneveckaya, The Educational Environment of a Higher Education Institution as a Factor in the Development of Students' Personal Competencies, 13.00.01., 27 (2010)

16. T.N. Pozdnyakova, World of Science. Pedagogy and Psychology, 5 (2019) https://mirnauki.com

17. A.P. Sukhonosov, Child in the Educational Space of a Megapolis: Collection of Materials of the II Interregional Scientific-Practical Conference, 1, 361 (2015)

18. E.Yu. Pochtareva, Bulletin of Perm University. Philosophy, Psychology, Sociology, 4, 563 (2017)

19. Order of the Ministry of Education and Science of the Russian Federation dated December 17, 1897 (2010)

20. A.V. Ivanov, Cultural Pedagogical Environment of a General Educational Institution as a Condition for the Development of a Child's Personality, 152 (APK and PPRO, 2005)

21. A.A Devyatkin, The Phenomenon of the Social Attitude in the Psychology of the $20^{\text {th }}$ Century, 309 (Kaliningrad University, 1999)

22. R.V. Ovcharova, E.R. Gizatullina, Development of the Moral Field of the Adolescent's Personality, 147 (Kurgan State University Press, 2011)

23. V.I. Pavlov, Bulletin of I. Yakovlev Chuvash State Pedagogical University, 4(80), 123 (2013) 
24. V.A. Yasvin, Educational Environment: From Modeling to Design, 365 (2001)

25. A.V. Borodina, Social Partnership as a Socio-Historical Phenomenon and Principles of Regulation of the Relationship of Social Groups, 13.00.01, 28 (2005)

26. O.A. Karabanova, Modern Foreign Psychology, 6(2), 15 (2017)

27. L.T. Potanina, T.N. Melnikov, A.S. Moskvina, Pedagogical Education and Science, 1, 34 (2016)

28. L.F. Novitskaya, Veliky Novgorod: Yaroslav-the-Wise Novgorod State University, 128 (2000)

29. Sh. Schwartz, Journal of the Higher School of Economics, 9(2), 43 (2012) 